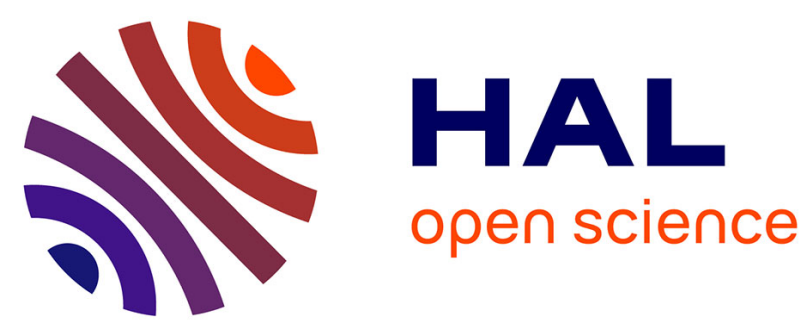

\title{
Improvement of the planning reliability by the integration of human skills in project risk management
}

François Marmier, Naoufel Cheikhrouhou, Didier Gourc

\section{To cite this version:}

François Marmier, Naoufel Cheikhrouhou, Didier Gourc. Improvement of the planning reliability by the integration of human skills in project risk management. GOL 2014 - 2nd IEEE International Conference on Logistics Operations Management, Jun 2014, Rabat, Morocco. art. 6887429 - p.125132, 10.1109/GOL.2014.6887429 . hal-01591964

\section{HAL Id: hal-01591964 \\ https://hal.science/hal-01591964}

Submitted on 25 Sep 2017

HAL is a multi-disciplinary open access archive for the deposit and dissemination of scientific research documents, whether they are published or not. The documents may come from teaching and research institutions in France or abroad, or from public or private research centers.
L'archive ouverte pluridisciplinaire HAL, est destinée au dépôt et à la diffusion de documents scientifiques de niveau recherche, publiés ou non, émanant des établissements d'enseignement et de recherche français ou étrangers, des laboratoires publics ou privés. 


\section{Improvement of the planning reliability by the integration of human skills in project risk management}

\author{
François Marmier \\ Industrial Engineering Department, \\ Université de Toulouse, MINES ALBI, \\ 81013 Albi, France \\ Marmier@mines-albi.fr
}

\author{
Naoufel Cheikhrouhou \\ Ecole Polytechnique Fédérale de \\ Lausanne (EPFL), \\ Laboratory of management and \\ production processes, \\ 1015 Lausanne, Switzerland \\ naoufel.cheikhrouhou@epfl.ch
}

\author{
Didier Gourc \\ Industrial Engineering Department, \\ Université de Toulouse, MINES ALBI, \\ 81013 Albi, France. \\ Gourc@mines-albi.fr
}

\begin{abstract}
To make the project more profitable, the actors that are the more adequate to perform the tasks have to be selected and decisions about how to deal with risks during the project have to be made. In this paper, the resource management is integrated into a project risk management approach. A decision support system is proposed to help the project manager decide which risk treatment strategy to develop and which assignments to plan to be the more efficient as well as less sensitive to the risks. Finally, a case study based on a weather forecasting station project is developed to validate this approach.
\end{abstract}

\section{Keywords}

Decision support system; proactive project planning; project management; resources management; risk; skills.

\section{INTRODUCTION}

In an extremely competitive and global market, the ability to adapt to change and to unforeseen events has nowadays become essential. Project managers have to take into account all adverse events that can have negative effects on the project. Therefore, project plans should integrate tasks to prevent risks when it is gainful, to be efficient and keep an advantage over competitors.

During the project, the occurrence of risks can induce changes in the planning and therefore on the project time and cost. In order to reduce the risk level in a project, it is necessary to define and apply a treatment strategy of the risk. Depending on the identified potential risks and associated risk treatment strategies, all the possible combinations lead to several scenarios of project development. To strategically manage the development of the project, the project manager (PM) has to decide which risk treatment strategies are the most profitable and should be developed.

Actors, resources carry out the innovation and the project development. Their availability is, most of the time, limited and their competencies are different from one another. The manner assignments are made may influence the realization of certain tasks that could be longer or shorter depending on the experience of the actor(s). The aggregation at the project level of differences observed at the task level changes the evaluation of the project indicators. Developping skill management in projects is necessary to assign adapted resource on tasks depending on the needed competencies. The PM has then to decide which assignments are the most efficient to perform the project (for example to limit delays and overrun costs).
An assignment is often built for a predetermined planning. Its efficiency is therefore indexed on the fact that the planning does not change. The fact that different futures (i.e. scenarios) are possible induces that the predetermined assignments would be less efficient than imagined. A crossed vision of the Project Risk Management (PRM) and the resource management led to the problematic of finding the best strategy of risk treatment and the best set of assignments integrating the knowledge of the multiple possible scenarios.

Currently, the classical methods of project management do not consider the combined effects of risk treatment and resource management on project planning. As an answer to this tactical and operational decision making problem, the aim of this paper is to propose a model that integrates skill management as a part of PRM in order to robustly optimize the cost and time of projects. The PM will consequently be able to decide which risk treatment strategy to develop and which assignments to deploy to be the least sensitive to risks while maintaining a high level of efficiency.

This paper is structured as follows. Section 2 gives an overview of the literature about the evaluation of risk and skill management in projects. Section 3 presents the model we propose to integrate the risks and skills management in the project management. In the fourth section, we detail the Decision Support System (DSS). In section 5, the case study of a meteorological station is developed. This approach is applied and the results are discussed. Finally, section 6 gives the conclusion and further perspectives of research in this field.

\section{DIFFICULTIES IN MANAGING PROJECT RISK}

The PM has to deal with an important amount of information to provide reliable planning (planning is reliable when its probability of being held is really high). Likewise, the PRM provides information on possible futures and helps choosing the best risk treatment strategy. Risk treatment activities, as well as initial project activities, are carried on by actors. Therefore, risk treatment strategy performance is influenced by the assignments decided. Resource management has to be considered as part of the PRM to make pertinent decisions.

\subsection{Risk management in project management}

The risk management methodologies refer to a standard process presenting the well-known steps: risk identification, risk evaluation and quantification, risk mitigation for treatment and/or impact minimization and risk monitoring [1-4]. Tixier et al. propose a classification of sixty two existing approaches [5]. They sort methods as being deterministic and/or probabilistic, but also qualitative or quantitative. 
Parallel to these global approaches, several authors propose methodologies to manage the risk in projects. Gourc (2006) [6] proposes a reading grid of the risk management approaches following two families: the symptomatic approach (called riskuncertainty) and the analytic approach that considers risk as an event that can affect the achievement of the project objectives [7]. Risk is described as an event, which has occurrence characteristics (potentiality to occur) and consequence characteristics on the project objectives (impact in the event of occurrence) [8]. Nguyen et al. propose Prorisk, which can model and evaluate the impact of risks on the project cost and the schedule cost [9]. They define the concepts of risk scenario, treatment scenario and project scenario. This project management approach uses synchronized processes of project schedule and risk management [10]. This helps answering to questions such as the selection of the best structure for the project [11]. Fang and Marle proposed a simulation-based model to evaluate risks and then to support the PM in making decisions regarding risk response actions [12]. The model integrates the risks and their interactions.

\subsection{Actors selection in planning}

Different works in the management of skills and competences in organizational structures have a focus on position qualification, responsibility identification and personnel allocation. The latter is generally studied with a focus on the allocation based on technical skills of the personnel considered. Indeed, it is proved that the efficiency of a system is closely linked to the allocation of personnel according to their skills [13]. A similar problem that is as well considered in the literature is the team building considering personnel skills. Fitzpatrick and Askin develop and test a mathematical programming formulation for the personnel selection problem for formation of effective human teams [14]. Hlaoittinun et al. propose an approach that generates a systematic formation of task and team member families [15]. Tsai et al. propose an integrated, efficient computational method based on design of experiments to solve the resource selection problem and reduce project cost and duration [16]. Tseng et al. develop a methodology based on fuzzy sets theory and grey decision theory [17]. Zakarian and Kusiak deal with the underlying complexities of the team selection process. They develop a methodology for team formation [18]. Fowler et al. develop a mixed integer programming model that determines different staffing decisions in order to minimize workforce related costs over multiple time periods [19].

Whereas those works take into account technical competences, very few works address the concept of competence from the human perspective. The richness of the literature in human resource management is one of the key elements for providing a better qualification of the concept of competence in comparison with the concept of skill. Indeed, LeBoterf defines skill management as the management of human resources to improve performance and achieve goals, and competence as the ability to efficiently combine material resources (specific to an activity such as instruments, machines, etc.) and Non-Material Resources (NMR) in order to accomplish an activity [20]. Bruneau and Pujos propose to categorize the resources in three categories: knowledge, know-how and interpersonal skills [21]. "Knowledge" is the set of theoretical resources incorporated in the persons or needed for an activity/task. "Know-how" is the incorporated technical resources that correctly allow achieving a task, based on earlier experience or ability. "Interpersonal skills"/"social attitude" are the resources that refer to ability to interact and communicate with other people. Pepiot et al. distinguish three types of skill: (1) Unitary skill is the ability to mobilize the NMR to respond to an activity, (2) Individual skill is the ability of an actor to mobilize and coordinate resources necessary to develop a set of activities or functions, and (3) Collective skill is the ability of a set of actors to mobilize and coordinate different resources necessary to develop a set of activities or functions, implicating different actors and tasks [22]. It represents the synergies between different actors of a group.

From a project scheduling/planning perspective, the issue of representing the personnel assignment problem with multiple skills is addressed in [23-27]. Different works address the assignment problem from a multi-objective point of view, where methaheuristics are used to find optimal solutions in the search space (see for instance [28] or [29]) or memetic algorithms for multi-objective optimization (see [29]). However, only the variability of technical skills is taken into account.

Actually, a very few number of researchers attempt to address the competence in the personnel assignment problem, such as Norman et al. that formulate the assignment problem in virtual manufacturing cells as a mixed integer programming model, in which they consider not only technical but also 'human' skills [30].

The literature review shows that conventional approaches of project planning and scheduling rarely include the skill Management to reduce risks. The impact of human competences has been neglected most of the time in decision-making. In fact, realistic problems have to take into consideration not only human competences as resource constraints, but also the global risks associated to human activity in achieving tasks, in terms respect of the project duration and cost. Therefore, in this paper, we propose a DSS based on a PRM approach. It integrates a new assignment model aiming to make the gap between the levels of acquired and required competences in project planning the smaller as possible. The proposed allocations of actors over all the project tasks ensure the reduction of both total cost and project makespan.

\section{A PROJECT RISK MANAGEMENT INTEGRATING HUMAN SKILLS}

\subsection{Assumptions}

The model we propose is based on three main hypotheses:

- the risk integration to the project management takes into account the deadlines and the cost criteria.

- the decisions of treatment strategy are taken for a given horizon of time.

- each task only requires one actor and one skill. Each skill is composed of a set of NMR. An actor can't process more than one task at the same time.

The objective of this work is not to assist the data gathering. But on the basis of all the data, the objectives of the model are (1) to analyse the possible scenarios, (2) to select the best treatment strategies, (3) to select the best assignments.

\subsection{Formulation of model}

\subsubsection{Data}

A project $P$ is described by its tasks $t(t=1 \ldots T), T$ being the number of tasks. The planning process gives an initial planning $P_{i}$ that does not integrate any risks or human resource particularities.

A task $t$ is defined by a skill $S_{s k}^{\mathrm{t}}(s k=1 \ldots S k)$ (or unitary skill) required for its process. $S k$ is the number of skills known in the organisation. The skills mobilize a set of NMR $r(r=1 \ldots W)$, with 
$W$ the number of NMR in the organisation. The level required by the task $t$ in the NMR $r$ is noted $L_{r e q}^{t \mid r}$

Each task is processed by an actor Act $_{\text {act }}(a c t=1 \ldots A), A$ being the number of actors in the organisation. Each actor has a set of skills $S_{s k}^{a c t}(s k=1 \ldots S K)$. For each $S_{s k}^{a c t}$, an actor mobilizes a set of NMR with respective acquired level $L_{a c t}^{t \mid r}$.

For any actor, the gap of time $\Phi_{a c t}(t)$ to perform the task $t$ is a weighted aggregation of the gap of resources from the skill required. Due to the difference of the resource importance to perform the task, the resource gaps are weighted by $W^{t \mid r}$ (i.e. the resource is essential for the development of the task or compromises the quality). The resource gap Gap act is the difference between acquire and require level of NMR. A gap of zero means that the Actor perfectly suits the Task.

$G a p_{a c t}^{t \mid r}=L_{a c t}^{t \mid r}-L_{r e q}^{t \mid r}$

Two functions of approximation $f_{\Delta T}{ }^{\prime}\left(G a p_{a c t}^{t \mid r}\right)$ and $f_{\Delta T}{ }^{\prime \prime}\left(G a p_{a c t}^{t \mid r}\right)$ are respectively used to model the evolution of the performance due to a positive or negative gap. They vary according to the NMR characteristic. Since most of the time, the performance is not simply proportional to gap, it allows a realistic weighting of the gain which is located between a maximal gain $G_{\max }^{t \mid r}$ and a minimal gain $G_{\min }^{t \mid r}$ on time, for each NMR and depends on the efficiency of the considered actor.

$\Phi_{\text {act }}(t)$

$=\sum_{r=1}^{W}\left\{\left(\begin{array}{c}f_{\Delta T}^{\prime}\left(G a p_{a c t}^{t \mid r}\right) * G_{\text {max }}^{t \mid r} * \theta_{a c t}^{t \mid r}+ \\ f_{\Delta T}^{\prime \prime\left(G a p_{a c t}^{t \mid r}\right)} * G_{\text {min }}^{t \mid r} * \overline{\theta_{a c t}^{t \mid r}}\end{array}\right) * W^{t \mid r}\right\} / \sum_{r=1}^{W} W^{t \mid r}$
$\forall a c t, \forall p$

Where $\theta_{a c t}^{t \mid r}$ is a Boolean variable. $\theta_{a c t}^{t \mid r}=1$ if the Gap is positive or null and $\theta_{a c t}^{t \mid r}=0$ else.

The duration of a task $t$ is then obtained by adding $\Phi_{a c t}(t)$, due to the efficience of the actor, to the initial duration $D_{\text {init }}(t)$ that does not depend on the actor.

$D_{a c t}(t)=D_{\text {init }}(t)+\Phi_{a c t}(t)$

A project is also described by its set $E_{R}$ of identified risks $R_{i}$ $(i=0 \ldots n), n$ being the number of identified risks in P. Each $R_{i}$ is characterised via the risk management process. A risk $R_{i}$ is also characterised by its period of occurrence, i.e. the tasks during which the risk can occur. Its probability $\operatorname{proba}\left(R_{i}\right)$ (the probability that the event related to $R_{i}$ occurs) and its impacts on costs $C I\left(R_{i}\right)$ and/or in delay $D I\left(R_{i}\right)$ on a task can be different from the period of occurrence. These probabilities and impacts are also called initial probability and initial impact. The fact that the task is running with a non optimal performance level is taken into consideration by the initial impact.

A risk scenario $S c R_{s}$ corresponds to the combination of the risks occurring during a project $P$. A project presenting $n$ risks leads to $2 n$ risks scenarios. Then $\operatorname{ScR}_{s} \quad\left(s=1, \ldots, 2^{n}\right)$ is a possible achievement with $k$ risks $(0 \bullet \mathrm{k} \bullet \mathrm{n})$ and the total number of risk scenarios, presenting $\mathrm{k}$ of the $\mathrm{n}$ identified risks, is equal to $\frac{\mathrm{n} !}{\mathrm{k} !(\mathrm{n}-\mathrm{k}) !}$. Its probability is $\operatorname{proba}\left(S_{c} R_{s}\right)$ (the probability that the events related to this risk scenario occur and that the other risks do not occur).

$\operatorname{proba}\left(\mathrm{ScR}_{s}\right)=\sum_{i=1}^{n}\left\{\begin{array}{r}\operatorname{proba}\left(\mathrm{R}_{i}\right) \text { if }\left(\mathrm{R}_{i} \in \mathrm{ScR}_{s}\right) \\ 1-\operatorname{proba}\left(\mathrm{R}_{i}\right) \text { if }\left(\mathrm{R}_{i} \notin \mathrm{ScR}_{s}\right)\end{array}\right.$

Each risk can be treated in various ways that can be preventive, corrective or a combination of several actions. A risk $R_{i}$ can be associated with one or more treatment strategies $\operatorname{StT}_{i j}(j=l \ldots m), m$ being the number of identified strategies for $R_{i}$. A treatment strategy $S t T_{i j}$ groups a set of treatment actions $A_{i j \alpha}(\alpha=1 \ldots a)$ to avoid or reduce the risk $R_{i}, a$ being the number of identified treatment actions. A treatment action can be materialized by a task to achieve and introduces three types of modifications to the WBS (Work Breakdown Structure) with some repercussions on the risk: addition of a new task, suppression of a task from the initial schedule and modification of an existing task.

A treatment strategy is a preventive strategy if it contains at least a preventive treatment action. Otherwise, it is a corrective strategy. If the strategy consists in running no action at all, it is noted as being an empty set such as $\emptyset$.

Finally, several treatment strategies are possible for each risk $R_{i}$. The definition of these strategies can lead to the appearance of treatment actions common to several risks. The set of all the identified $S t T_{i j}$ for a risk $R_{i}$ is written $S t R_{i}$.

Then $S t R_{i}=\emptyset, S t T_{i l}, \ldots, S t T_{i p}, \ldots, S t T_{i m}$ and $\operatorname{Card}\left(S t R_{i}\right)=m+1$.

A treatment scenario $S c T_{d}(d=1 \ldots D)$ corresponds to a combination of the treatment strategies chosen to deal with the different risks of a project. The set of treatment scenarios is given by: $E_{S c T}=\prod_{i=1}^{n} S t R_{i}$

For each $P, E_{S C T}$ may contain a set of preventive treatment scenarios $E_{S c T_{\text {prev }}}$ and corrective treatment scenarios $E_{S c T_{\text {correc }}}$.

The $\operatorname{proba}\left(R_{i} \mid S t T_{i j}\right)$ is the probability that the event related to $R_{i}$ occurs, knowing that $S t T_{i j}$ (preventive strategy) has been achieved. This probability, as well as the impacts $C I\left(R_{i} \mid S t T_{i j}\right)$ and $D I\left(R_{i} \mid\right.$ $\left.S t T_{i j}\right)$, are then qualified "reduced probability" and "reduced impact".

A project scenario $S c P_{p}(p=1 \ldots P)$ is defined as a possible project achievement that is built with a risk scenario and treatment scenario $\left(S c P_{p}=<P_{i}, S c R_{s}, S c T_{d}>\right)$. The set of project scenarios $E S$ is obtained by combining the set of occurring risks (or a risk scenario) and the set of determined treatment actions (or treatment scenario).

$\operatorname{proba}\left(S c P_{p}\right)$ is the probability of a given $S c P_{p}$. It takes into account (1) the probability of the occurring risks ${ }^{p}\left(R_{i} \in S c R s\right),(2)$ the probability that several risks do not occur $\left(R_{i} \notin S c R_{s}\right)$, (3) the probability of the occurring risks $\left(R_{i} \in S c R_{s}\right)$ knowing that a Treatment strategy is developed $\left(S t T_{i j} \in S c T_{d}\right)$ (4) the probability that $R_{i}$ does not occur $\left(R_{i} \notin S c R_{s}\right)$ knowing that a preventive strategy has been processed and the initial probability has been modified $\left(S t T_{i j} \in S c T_{d}\right)$.

$$
\operatorname{proba}\left(S c P_{p}\right)=\prod_{i, j}^{R_{i} \in S c R_{s}, S_{T} T_{i j} \in S c T_{d}}\left\{\begin{array}{l}
\operatorname{proba}\left(R_{i}\right) \\
1-\operatorname{proba}\left(R_{i}\right) \\
\operatorname{proba}\left(R_{i} \mid S t T_{i j}\right) \\
1-\operatorname{proba}\left(R_{i} \mid S t T_{i j}\right)
\end{array}\right.
$$

For each project scenario, the duration $D\left(S c P_{p}\right)$ is obtained using the PERT method. After having adapted the initial schedule in accordance with the studied scenario (modified duration, tasks added or removed), the project scenario duration is computed by 
taking into account the earliest starting dates. The following equation shows how the variations of skill are integrated in the calculation of the duration of the critical path:

$D\left(S c P_{p}\right)=\sum_{a c t=1}^{A c t} \sum_{t=1}^{T} D(t) * Z_{a c t}^{t} * \gamma^{t}$

Where $\gamma^{t}$ is a Boolean variable that represents the position of the task $t$ on the critic path, and its potential influence on the project total time. $\gamma^{t}=1$ if the task is on the critical path. 0 if not. $Z_{a c t}^{t}$ is also a Boolean variable that indicates whether the actor processes the task. $Z_{a c t}^{t}=1$ if act process the task $t .0$ if not.

The cost of a project scenario is noted $C\left(S c P_{p}\right)$. It is composed of direct costs $D C\left(S c P_{p}\right)$ and indirect costs $I D C\left(S c P_{p}\right)$.

$\mathrm{C}\left(S c P_{p}\right)=D C\left(S c P_{p}\right)+I D C\left(S c P_{p}\right)$

The direct cost $\mathrm{DC}\left(\mathrm{ScP}_{\mathrm{p}}\right)$ includes the direct cost of the tasks, the remaining part of the direct cost of the occurring risks, the treatment strategies (materials, tools, parts etc.). The indirect cost $I D C\left(S c P_{p}\right)$ includes the cost of the $T$ tasks that constitute the chosen $S c P_{p}$. The planning integrates all tasks (initial and risk treatment) with their (modified/or not) durations due to delays and the efficience of the actors in charge.

$I D C\left(S c P_{p}\right)=\sum_{a c t=1}^{A c t} \sum_{t=1}^{T} D(t) * P_{a c t} * Z_{a c t}^{t}$

Where $P_{a c t}$ is the actor rate, in unit of money per unit of time.

\subsubsection{Objective functions}

In a project context, different decisions are planned to be made over the different phases of project conception and management in order to reduce and control the level of risks. The project management team plan to go through different decision (D1 to D4) to reach its objectives. Its first decision (D1) aims to select the preventive risk treatment strategy. Despite the fact that human resources' skills are rarely considered when estimating the time of tasks to reduce the risks of delay, the second decision (D2) is the assignment of the actors to the project tasks (including activities and risk prevention). Decision D3 consists in deciding which corrective actions should be carried on facing an undesirable set of events. Finally D4 consists in assigning actors to the task inserted in the planning for the corrective risk treatment. D1 and D2 are plan to be made during the preparation phase of the project, contrary to D3 and D4 that are plan to be made to react when events occur.

Finding the best risk treatment strategies and the best allocation of actors is often based on antagonist optimization functions. Such decisions show how expensive efficiency can be. Then before the launch of the project, the PM should have decide D1 to D4 in order to:

(1) minimize the time of the project: $\min D(P)$

(2) minimize the cost of the project: $\min C(P)$

\section{RESOLUTION APPROACH}

To make reliable planning, the proposed approach combines both proactive and reactive risk management. At a tactical level of the project management, the approach considers possible preventive risk treatments and actor assignments. At an operational level, it considers potential reactive risk management. The approach consists of two main phases: (1) for a given project, generate the set of project scenarios. (2) Resolve the decision tree to strategically choose the risk treatment strategy and a robust and efficient set of human resource assignments.

\subsection{Generation of the project scenarios}

During the preparation of a project, the way of managing risks has to be chosen. The approach we propose uses data in relation with the project in its classical view: the different tasks planned, the risks, their associated treatment actions. These data are supposed to be collected on the basis of expert knowledge. Some data also come from human resources: skills to perform the tasks and consequently their costs. Therefore, our method includes input data provided by the schedule process (management team), from the risk management process and from the support process (the human resource service).

Based on these data, the set of the possible project scenarios are generated. A project scenario includes the different tasks, a risk scenario and an associated and chosen treatment scenario. This set of project scenarios gives an overview of the possible futures. To complete the vision of the possible scenarios, the resource assignment possibilities are computed, keeping in mind the fact that the cost and the project duration both have to be minimized. Depending on the size of the problem, find the multiple optimal solutions in a single simulation run may be tricky and may require the use of an Evolutionary Algorithm (EA). Several EA have been proposed in the literature [31]. As it has been suggested in many comparative studies of multi-objective evolutionary algorithms, the elitist non-dominated sorting genetic algorithms (NSGA-II) $[32,33]$ prove sufficient, with a good distribution of nondominated solutions. Therefore, the Pareto optimal solutions, that are the best possible assignments (regarding the cost and the time criteria), are obtained for each project scenario.

\subsection{Resolution of the decisional problem}

Since the project scenarios are generated and the best possible set of assignments is computed in the phase (1), our approach gives a different perspective from the classical approach (section 3.2.3) and then becomes proactive. The phase (2) is composed of three steps. The decisions can be anticipated: (a) consists in selecting a set of assignments for the whole tasks of the project scenario (D4 and D2) (b) D3 can be made, knowing the best assignments for each task in D4 and D2. (c) Then D1 can be made, knowing all the possible decisions included in the DT.

(a) The phase (1) previously described gives the visibility on the actors that are frequently proposed over all Pareto fronts and therefore for each particular task. The fact that actors are part of assignments leading to Pareto optimal solutions proves their performance. Besides, if an actor frequently is a member of a Pareto solution, it means that its assignment should be robust on project modifications, since it is proposed in various situations and gives good results as far as the criteria are concerned. The frequency is measured unitarily, per task, since different tasks may not be encountered in all project scenarios. Therefore among all Pareto solutions and for each task, the most frequently assigned actors are selected. A set of actors for each task can then be selected and the combinations of possible set of assignments 
are computed. They lead to a set of possible combination of assignments (i.e. Actor 1 to task 1 and Actor 2 to task 2; Actor 1 to task 1 and Actor 1 to task 2...).

(b) D3 consists in choosing corrective strategies, for each ScR, knowing that a selection of sets of assignments has been previously done. A measure of the criticality of each project scenario allows evaluating the project scenarios. It is based on an aggregated criterion representing a global impact. Therefore D3 consists in selecting, for each ScR, the corrective strategy that minimizes the criticality.

(c) D1 is the last step that composes the resolution phase. It consists in avoiding the worst possible cases (project scenarios) as defined by the Savage's criterion often used in decision-making theory [34] by choosing the preventive strategy StTprev. Minimizing the maximum criticality $\mathrm{Cr}_{\max }(\mathrm{ScP} / \mathrm{StTprev}$ ) (also called in similar context regret) when the assessment of each scenario is known can measure the regret that the decision-maker would have if he had he preferred an action to one another.

\section{CASE STUDY}

To show the methodological contribution of these research works, we propose a case study that examines the condensed case of a building project for a weather forecasting station. Different actors from different industrial sectors took part in this project and provided us with the data. This example can be extrapolated to problem with a higher size. More details on this condensed version will be provided at the conference.

\subsection{Presentation of the project and actors}

The project comprises six tasks (T1-T6) with different durations, costs, predecessors, required NMR and associated levels and their respective weights in their relation to others NMR. The maximal and minimal gains on time for a given NMR are also given.

Three main risks are identified by the risk management process (R1-R3). Therefore, in this project, the set of the risk scenarios contains $2^{3}(8)$ risk scenarios. Each risk is characterised by a probability, a period of occurrence, an initial impact (cost and duration) and associated treatment strategies.

Treatment strategies can be preventive (p) or corrective (c). They can modify the project through the addition of a new task or the modification of an existing one.

Competence management provides the project with the NMR and the associated level required for each task, but also the level acquired by actors for each NMR. Ten NMR are identified. Due to the particularity of certain tasks, several resources are required in more than one task.

Two sets of actors have been identified: (1) construction specialists or (2) technical specialists. (1) Three actors (No 1 to 3 in table 1) are considered as construction specialists and are trained for tasks like T1, T2, T3 and T5. (2) The two last actors, the technical specialists, are specialized in the type of tasks containing measuring equipment like in $\mathrm{T} 4$ and $\mathrm{T} 6$.

\subsection{Results}

Phase (a) of the approach shows that four different preventive treatment strategies of risk are possible. R1, R2 and R3 may be combined to generate 8 risks scenarios. To react to this set of risk scenarios, twelve different corrective strategies are possible. At that stage and without considering a possible assignment of the actors, the decision tree presents 48 leaves or project scenarios. By generating the combination of assignments for each of the 48 project scenarios, using the genetic algorithm, a total of 679 solutions (project scenario with assignments) are retained as being Pareto optimal.

Phase (b), which is the resolution phase of the approach, is decomposed in three steps. It starts with the set of 679 assigned project scenarios and gives the PM the best couple \{risk treatment strategy, assignment for each task $\}$.

Table 1 presents for each task the frequency of selection of each actor within the 679 pareto solutions. For example, for task 1, actor 1 is selected in $81.6 \%$ and actor two is selected in $18.5 \%$ of the Pareto solutions. The actors frequently assigned (up to the determined threshold) are the ones presenting their frequency in bold, in table 6 , for each task. Therefore, one actor is selected for the tasks 1 (actor 1) and 2 (actor 2) and two actors are selected for the tasks 3 (actor 2 and 3), task 4 (actor 1 and 3), task 5 (actor 1 and 2) and task 6 (actor 1 and 5). By combining this unitary selection of assignments, 16 sets of representative assignments are obtained. Only four sets of assignments on these 16 are found on the 679 Pareto solutions. These four assignments are common to $25.6 \%$ of the 679 solutions.

Table 1 Frequency (\%) of selection of actors in the assignments

\begin{tabular}{ccccccc}
\hline \multirow{2}{*}{ Actor } & \multicolumn{7}{c}{ Task No } \\
\cline { 2 - 7 } & 1 & 2 & 3 & 4 & 5 & 6 \\
\hline 1 & $\mathbf{8 1 . 6}$ & 23.0 & 0.0 & $\mathbf{5 8 . 9}$ & $\mathbf{4 1 . 1}$ & $\mathbf{2 9 . 5}$ \\
2 & 18.4 & $\mathbf{7 7 . 0}$ & $\mathbf{5 9 . 6}$ & 0.0 & $\mathbf{4 0 . 4}$ & 0.0 \\
3 & 0.0 & 0.0 & $\mathbf{4 0 . 4}$ & $\mathbf{4 1 . 1}$ & 18.6 & 10.9 \\
4 & 0.0 & 0.0 & 0.0 & 0.0 & 0.0 & 19.7 \\
5 & 0.0 & 0.0 & 0.0 & 0.0 & 0.0 & $\mathbf{3 9 . 9}$ \\
\hline
\end{tabular}

Table 2 shows for each preventive strategy the set of assignments that minimizes the maximal criticality for all scenarios. The same set of assignments is proposed in each sub branch of the tree. The last column presents the maximal criticality obtained for the different ScR with this assignment. The value of the last column, written in bold, corresponds to the minimal "maximum criticality"

Regarding this case study, the final decisions would be to apply the strategy StT31 and to assign to the tasks 1 and 4 the actor 1, to the tasks 2 and 5 the actor 2 , to the task 3 the actor 3 and to the task 6 the actor 5. During the running phase in front of the occurrence of Risk 2, the PM would choose to apply the corrective actions that composes StT21.

\subsection{Analysis and discussion}

This approach has been developed to help the decision-maker with the combinatorial complexity of possible futures for a project. Therefore, it helps to choose project strategies of risk treatment and actors that will achieve initial tasks of the project and risk treatment tasks. The manager can then find the best 
balance between benefits and risks and be more confident regarding the project estimation in time and cost.

Table 2 Details of the selected resources per task

\begin{tabular}{|c|c|c|c|c|c|c|c|}
\hline \multirow[t]{2}{*}{$\begin{array}{l}\text { Preventive } \\
\text { strategies }\end{array}$} & \multicolumn{6}{|c|}{$\begin{array}{c}\text { Task } \\
\text { No }\end{array}$} & \multirow[t]{2}{*}{$\begin{array}{c}\text { Criticality } \\
\max \end{array}$} \\
\hline & 1 & 2 & 3 & 4 & 5 & 6 & \\
\hline$\varnothing$ & 1 & 2 & 3 & 1 & 2 & 5 & 0.2583 \\
\hline StT31 & 1 & 2 & 3 & 1 & 2 & 5 & 0.1808 \\
\hline StT32 & 1 & 2 & 3 & 1 & 2 & 5 & 0.1821 \\
\hline StT33 & 1 & 2 & 3 & 1 & 2 & 5 & 0.2946 \\
\hline
\end{tabular}

(1) Concerning the approach, different choices have been made regarding the criteria used at the different decision steps. To evaluate a project scenario, the cost, time and probability are used. They have been chosen to answer to the problem, however other criteria could give complementary information such as the total probability to respect a given contractual agreement (for D1). Several statistical criteria have been tried comparing the maximal criticality such as the dispersion through ranges of values. However, the minimal criticality is very low and close to zero. A deeper analysis of the possible criteria could then lead to a more robust and more informative approach.

The proposition of the best assignments is based on the gap of NMR. When the NMR acquired equal the required ones, the gap equals 0 . Then there is no variation in the duration of the task and the actor perfectly suits the task. This approach integrates the fact that a ceiling limit can be reached to be representative of the reality. When the PM decides the assignments for the corrective task the assignments for the rest of the project are supposed to be known. Different sets of assignments can lead to nearly similar results. However, the approach leads to choosing one only in the end. It could be pertinent to propose them to the PM as a solution of substitution in case of problem.

The decisions taken over the steps (b) and (c) of the approach differ in their operationalisation. The preventive actions decided in step (c) conduct the PM to integrate new tasks in the planning and to assign skilled actors, contrary to the corrective actions that are decided in case the risks occur. Consequently, the PM books actors in case undesirable events occur. Actors are not directly assigned and problems can happen if they are effectively assigned to other projects over the same period of time.

Even if the approach has been designed as a general one, such an approach integrating metaheuristics, such as a genetic algorithm, cannot be fully automatized. Different parameters have to be calibrated to find the best rapidity/efficiency balance, depending on the context. That way it should be usable in other industrial contexts, but the feasibility still has to be proved.

(2) The case study has been limited to a reduced number of tasks, risks, risk treatment actions, actors and skills. They illustrate the complexity, as well as making it understandable. The DSS gives the orientation to the PM at each decision node. He can therefore decide to modify the project planning to preventively deal with the risks, knowing the ability of the actors and the means of reaction. In case of modification of the context and/or of the project, the approach can be re-launched. If the project is important, the approach can also be launched at the main milestone to make the planning correspond with the new information. The difficulty of deciding is then illustrated and the solution we propose gives an answer to the problem. Even if the PM considers a more detailed vision of the planning, if the Risk Manager diagnoses more risks and if the business managers consider more different skills, this approach would have successfully applied, highlighting the consequences of decisions.

\section{CONCLUSION AND PERSPECTIVE}

The innovation, inherent to project definition, may conduce to technical and organizational difficulties. The PM has to manage the actors to overcome these difficulties. However, the literature survey shows that human resource and competencies are too little considered in project management tools. It may be problematic, since the competitiveness and the profitability depend on the ability to propose realistic contractual agreements and to meet commitments. To be as precise as possible in project estimations and to be robust with disturbing events, risks should be anticipated and human resources should no longer be perceived as generic. If the benefit of the assignment of one particular actor to a specific task may easily be evaluated, each risk and each risk treatment tasks generate different project scenarios with different costs and durations. Therefore, an efficient set of assignments for one particular project scenario may not be considered efficient for another one. Regarding all the possible project scenarios, it is difficult to choose a set of assignments as being the best. Then, there is a need for a DSS to find the set of assignments that would be a relevant global solution considering the different possible future solutions.

To estimate the consequences of decisions in project, we propose an approach to model and evaluate the impact of risks and skills assignment on the project duration and cost. This approach is based on a synchronized process between risk management and project management. Knowledge is integrated to human resources skill. We used the concepts of risk scenario, treatment scenario and project scenario to characterize and evaluate the project futures. We illustrate our approach through a case study from the building area. This methodology analyses the possible scenarios, evaluates the global risk level and selects the best treatment scenarios at any time. An estimate of the global risk level of each project scenario can be made and gives a vision of the best possible decisions: choose the best combination "risk treatment / assignments" of actors!

The main perspective of this research work is at a strategic level. To successfully reach the requested level of innovation, different variants of the project are possible. A perspective would be to enhance the model so that the DSS can indicate the best variant of the project, knowing its repercussions on the risk and risk strategies as well as on the possible assignments.

\section{ACKNOWLEDGMENTS}

The authors would like to thank Mr Gonzallo and Mr Sundaram for their participation to the developments. They also would like to address special thanks to Mrs Carbonnel for her contribution to 
the platform developments and to Mrs Fournier for her contribution to the paper quality.

\section{REFERENCES}

[1] Canadian Standard Association. 1997. CAN/CSA-Q850: Risk Management, Guideline for Decision Makers.

[2] British Standards Institution. 2000. BS 6079-3: Project Management: Guide to the management of business related project related.

[3] International Organization for Standardization. 2009. ISO 31000, Risk management - Principles and guidelines.

[4] Project Management Institute. 2009. Practice Standard for Project Risk Management, Project Management Institute Ed.

[5] Tixier J., Dusserre G., Salvi O. and Gaston D. 2002. Review of 62 risk analysis methodologies of industrial plants, Journal of Loss Prevention in the Process Industries, Vol. 15 No.4, pp.291-303.

[6] Gourc, D. 2006. Towards a general risk model for piloting goods- and service-related activites (Vers un modèle general du risqué pour le pilotage et la conduite des activités de biens et de services), HDR de l'Institut National Polytechnique de Toulouse, France (In french).

[7] Carter, B., Hancock, T., Morin, J. and Robin, N. 1996. Introducing RISKMAN: the European project risk management methodology, The Stationery Office, England.

[8] International Organization for Standardization. 2002. ISO Guide 73, Risk management -- Vocabulary - Guidelines for use in standards.

[9] Nguyen, T.H., Marmier, F., Gourc, D. 2010. A decisionmaking tool to maximize chances of meeting project commitments, International Journal of Production Economics.

[10] Pingaud, H. and Gourc, D. 2003. Approach of controlling an industrial project by the risk analysis (Démarche de pilotage d'un projet industriel par l'analyse des risques), 5th Congrès International Franco-Québécois de Génie Industriel, Canada (in french).

[11] Marmier, F., Gourc, D., Laarz, F., 2013. A risk oriented model to assess strategic decisions in new product development projects. Decision Support Systems, doi: 10.1016/j.dss.2013.05.002.

[12] Fang C., Marle F. 2012. A simulation-based risk network model for decision support in project risk management, Decision Support Systems, Vol. 52 No.3, pp.635-644.

[13] Juran, D.C. and Schruben, L.W. 2002. Incorporating worker personality and demographics in predicting system performance, Journal of Operations Management.

[14] Fitzpatrick, E.L., Askin, R.G. 2005. Forming effective worker teams with multi-functional skill requirements, Journal of Computers \& Industrial Engineering. Vol. 48, 593-608.

[15] Hlaoittinun, O., Bonjour, E., Dulmet, M. 2007. A team building approach for competency development, International Conference on Industrial Engineering and Engineering Management, IEEE, Singapur.

[16] Tsai, H.T., Moskowitz, H., Lee, L.H. 2003. Human resource selection for software development projects using Taguchi's parameter design, European Journal of Operational Research, 151, pp.167-180.

[17] Tseng, T.L., Huang, C.C., Chu, H.W., Gung, R.R. 2004. Novel approach to multi-functional project team formation, International Journal of Project Management, Vol. 22, pp.147-159.

[18] Zakarian, A., Kusiak, A. 1999. Forming teams: an analytical approach, IIE Transactions, Vol. 31, pp.85-97.

[19] Fowler, J. W., Wirojanagud, P., \& Gel, E. S. 2008. Heuristics for workforce planning with worker differences, European Journal of Operational Research, Vol. 190 No.3, pp.724-740.

[20] LeBoterf G. 2002. Ingénierie et évaluation des compétences, 4th edition, Editions d'Organisation, (In French).

[21] Bruneau J.M. and Pujos J.F. 1992. Le management de la connaissance dans l'entreprise ressources humaines et systèmes dinformation, Editions d'Organisation, Paris. In French).

[22] Pepiot G., Cheikhrouhou N., Fürbringer J.M., Glardon R. 2008. A fuzzy approach for the evaluation of competences, International Journal of Production Economics, Vol.112, No.1, pp.336-353.

[23] Certa, A., Enea, M., Galante, G., \& Manuela La Fata, C. 2009. Multi-objective human resources allocation in RD projects planning, International Journal of Production Research, Vol. 47 No.13, pp.3505-3523.

[24] Kuo, Y., \& Yang, T. 2007. Optimization of mixed-skill multi-line operator allocation problem, Computers and Industrial Engineering, Vol. 53 No.3, pp.386-393.

[25] Şen, C. G., \& Çinar, G. 2010. Evaluation and pre-allocation of operators with multiple skills: A combined fuzzy AHP and max-min approach, Expert Systems with Applications, Vol. 37 No.3, pp.2043-2053.

[26] Ballesteros-Pérez P., González-Cruz Ma. C., FernándezDiego M. 2012. Human resource allocation management in multiple projects using sociometric techniques, International Journal of Project Management, Vol. 30, No.8.

[27] Marmier, F., Varnier, C., Zerhouni, N. 2009. Proactive, Dynamic and Multi-Criteria Scheduling of Maintenance Activities, International Journal of Production Research, Vol. 47 No.8, pp.2185- 2201, doi:10.1080/00207540802311106.

[28] Huang, J., Wang, X., \& Chen, R. 2010. Genetic algorithms for optimization of resource allocation in large scale construction project management. Journal of Computers, Vol.5 No.12, pp.1916-1924.

[29] Chen, A. H. L., \& Chyu, C. 2010. Applying memetic algorithm in multi-objective resource allocation among competing projects, Journal of Software, Vol. 5 No.8, pp.802-809.

[30] Norman, B.A., Tharmmaphornphilas, W., Needy, K.L., Bidanda, B. and Waner, R.C. 2002. Worker assignment in cellular manufacturing considering technical and human skills, International Journal of Production Research, Vol.40 No.6, pp.1479-1492.

[31] Deb K. 2001. Multi objective optimization using evolutionary algorithms, John Wiley \& Sons. 
[32] Zitzler E. 1999. Evolutionary Algorithms for Multi Objective Optimization: Methods and Application, $\mathrm{PhD}$. thesis, ETH, Zurich.

[33] Zitzler E., Deb K., Thiele L. 2000. Comparison of multi objective evolutionary algorithms: Empirical results,
Evolutionary Computation archive, Vol. 8 No.2, pp.173 195.

[34] Petar J. 1999. Application of sensitivity analysis in investment project evaluation under uncertainty and risk, International Journal of Project Management, Vol. 17 No.4, pp.217-222. 